\title{
Lexical Inferencing in Newspaper Columns: An Introspective Study
}

\author{
Awais Shafiq ${ }^{1}$, Abdullah Shafiq ${ }^{2}$, Adnan Tahir $^{3} \&$ Muhammad Akbar Sajid ${ }^{4}$ \\ ${ }^{1}$ Nishat College of Science, Multan, Pakistan \\ ${ }^{2}$ Australian Education Counsel, Multan, Pakistan \\ ${ }^{3}$ Riphah International University, Faisalabad, Pakistan \\ ${ }^{4}$ National University of Modern Languages, Multan, Pakistan \\ Correspondence: Awais Shafiq, Nishat College of Science, Multan, Pakistan. E-mail: \\ awaisshafiq345@gmail.com
}

Received: August 5, 2018 Accepted: October 5, 2018 Online Published: December 29, 2018

doi:10.5539/ijel.v9n1p367 URL: https://doi.org/10.5539/ijel.v9n1p367

\begin{abstract}
The significance of vocabulary in second or foreign language cannot be denied. The study explores the knowledge sources used by ESL learners in generating the meanings of the unknown words found in the columns of a daily Dawn. The study also investigates the effect of text length and syntactic property of unknown words in the inferential behaviors of learners. The participants of the study were chosen randomly from BS English, Govt. Emerson College, Multan. The amended taxonomy of knowledge sources and clues given by Bengleil and Paribakht (2004) was used in the study. The inferences verbalized their thoughts while guessing the meanings of the unknown words. The higher group was more successful in their guessing than the lower group. The study also found out that text length and the syntactic property of an unknown word his impact on the process of lexical inferencing. The study recommends the strategy of lexical inferencing as it facilitates reading comprehension and enhances lexical knowledge of learners.
\end{abstract}

Keywords: lexical inferencing, reading comprehension, Introspection, linguistic clues, non-linguistics clues

\section{Introduction}

Whenever the learners of a second or foreign language are asked to read texts written in target language, they encounter unknown words in these texts. It is found a difficult task to consult a dictionary every time for the unknown words found in texts. Lexical inferencing is a cognitive task. It can be used as a compensatory strategy for overcoming the deficiency of learners. Language used in print media has a special attraction for the researchers. One cannot deny the significance of newspapers for language teaching. There are many avenues of newspaper which can be explored. The news stories, the editorials, the letters to the editors and the newspaper columns have their own syntactic, semantic, pragmatic and lexical features. These genres of newspaper are acknowledged by the language experts. In the newspaper columns the journalists express their views on the current issues. They have their own ideologies and try their best to have influence on the readers.

\subsection{Statement of the Problem}

English is the language which has an enormous size of vocabulary. English vocabulary is on the increase with the passage of time. English dictionaries are flooded with new words every year. ESL learners are often provided with the lists of words. Even the knowledge of the decontextualized words becomes insufficient in reading comprehension. Words have their meanings in the context in which they are used. Various shades of meanings can be understood according to the context provided by texts. English is a polysemous language. There is a long list of words which have multiple meanings. They like reading in English more if they find only known words in texts. It is useful to find alternate ways to increase the word power of learners.

\subsection{Research Questions}

1) What types of knowledge sources in lexical inferencing are used by lower-proficiency learners and higher-proficiency learners while deducing the meanings of the unknown words encountered in Pakistan English newspaper columns?

2) What is the effect of text length on lexical inferencing? 
3) What is the impact of syntactic property of an unknown word in the inferential behavior of learners?

\section{Literature Review}

Second or foreign language learning cannot take place without ample exposure or input. When the learners interact with a text they have to confront with linguistic problems due to their limited knowledge of the target language. Like native speakers, the learners have compensatory capability though they may have additional encoding problems (Bailystok \& Kellerman, 1987). The unknown words in the text become hurdles in comprehending the text. Lexical inferencing procedures adopted by the language learners help them comprehend the text. Carton (1971, p.45) has pointed out that "in inferencing, attributes and contexts that are familiar are utilized in recognizing what is not familiar." Haastrup (1991) has given a comprehensive definition of lexical inferencing as she states that lexical inferencing

"involves making informed guesses as to the meaning of a word in light of all available linguistic cues in combination with the learner's general knowledge of the world, her awareness of the co-text and her relevant linguistic knowledge." (ibid, 1991, p.40)

The processes involved in "negotiating meaning' are seen by Haastrup (1991) as a source of theoretical understanding of learners' strategies as well as an element of second language teaching methodology. Meaning does not lie exclusively in the code as meaning potential, but meaning is developed in interaction with the users of that code (Haastrup, 1991). The following figure gives an account of the cues learners uses to infer the meanings of the unknown words.

\begin{tabular}{|c|c|}
\hline \multirow{2}{*}{ Top Level } & Context \\
\hline & Semantics \\
\hline \multirow{9}{*}{ Bottom level } & Collocation \\
\hline & Syntax \\
\hline & Word class \\
\hline & Word Origin \\
\hline & Lexis \\
\hline & Morphology \\
\hline & Orth \\
\hline & ography \\
\hline & Phonology \\
\hline
\end{tabular}

Figure 1. Hierarchy of cue levels (Haastrup, 1991, p. 133)

In order to generate meaning for unknown words the learners use three types of clues as described by Carton (1971).

1) When using interlingual cues, the learners draw on their ability to recognize formal similarities between the words in the target language and words in the mother tongue or any other language they know

2) When using extralingual cues, they draw on their background knowledge or knowledge of the word.

3) When using interlingual cues, they draw on their ability to analyse the words of the target language they already know into their morphemes.

Lexical inferencing has attracted the researchers' attention. It is considered the primary activity through which lexical development occurs in the second or the forging language (Deschambault, 2012). The learners use different knowledge sources to infer meaning for unknown words they encounter in a text (Bengleil \& Paribakht, 2004; Elgort, 2017; Haastrup, 1989, 1991; Jelic, 2007; Naasaji, 2003, 2004; Qian, 2005; Wesche \& Paribakht, 2010).

Bensoussan and Laufer (1984) have explored the extent to which context helps lexical inferencing, word guessability and the level of the students. Haastrup (1991) has found out that the higher-proficiency learners surpassed the lower-proficiency learners in their use of intralingual source and interlingual source. The 
high-proficiency learners were able to choose the suitable knowledge sources than the low-proficiency learners. They made a broader repertoire of knowledge sources used in lexical inferencing, made better use of the whole range of knowledge, and adopted more skills towards various items. Huckin and Bloch (1993) have suggested that learners should use global clues with local clues in order to make a successful attempt. Jelic's study (2007) has examined the lexical inferencing strategies used by Croatian learners of French as a foreign language. They were found to employ different lexical inferencing strategies. It was observed that global strategies were used more frequently than local strategies.

$\mathrm{Hu}$ and Nassaji (2012) examined the relationship between the ease of inferencing, the inferential strategies employed by learners and the retention of the meanings learnt through lexical inferencing. The learners should use form-focused and meaning-focused strategies in order to arrive at the correct guessing. In another study Hu and Nassaji (2014) investigated the inferential strategies used by eleven Chinese ESL learners in their attempts to infer the meanings of the words from the text. What distinguished both types of the inferencers was the quality, not the quantity of the strategy they used.

\section{Research Methodology}

\subsection{Participants}

The participants who took part in the study were twenty four. All of them were ESL learners. They were enrolled for BS-English 4-year programme at Govt. Emerson College, Multan, Pakistan. Twenty students (5 males and 5 females from semester I and 5 males and 5 females from $8^{\text {th }}$ semester) were selected randomly for the main study. Their age ranged from 18 to 25 .

\subsection{Texts}

Two column articles were selected. Both articles were written by two different writers. In the first article Pakistan's Moscow Option the writer suggests that Pakistan should take advantage of the option of Moscow as America is bending towards India (Appendix A). The good strategic relation with Russia is the need of the hour. The length of the article is 960 words. In the second article OBOR and CPEC the columnist describes OBOR (One Belt, One Road) and CPEC in detail (Appendix B). The length of the article is 780 words. Both the articles were published in Daily Dawn, a Pakistani English newspaper (www.dawn.com).

\subsection{Target words}

The target words were selected by the students of same classes. These students did not take part in the study. There were 36 target words - 21 in Pakistan's Moscow Option and 15 target words in the OBOR and CPEC. There were 16 verbs, 13 nouns and 7 adjectives in both articles. The percentage of the target words in Pakistan's Moscow Option was 2.19 while the percentage of targets words $O B O R$ and CPEC was 1.92.

\subsection{Data Collection}

The study collected verbal protocols from the participants of the study. In these protocols they describe aloud their thoughts verbally. Despite some drawbacks, verbal protocols give better understanding of the cognitive processes the participants undergo while performing a task. As Payan (1994, p.24) has remarked that "verbal protocols may not be perfect, but they are a very satisfactory tool to include in the toolbox of psychologists and other behavioral scientists". Introspective method is usually called con-current method as it gives an on-line record of the thoughts of the participants during a task. Contrarily, the retrospective method gives the record of the thoughts of the participants after the completion of a task. The study selected the introspective method for data collection.

The verbal protocols were collected after the participants were taught to verbalize their thoughts during the process of deducing the meaning of the unknown words in the newspaper columns. Their cognitive thoughts were tape-recorded and transcribed while using a coding scheme for analysis. The thoughts reflect not only short-term memory processing, but also internal deliberation (Ericson \& Simon, 1993).

\subsection{Theoretical Framework}

The study used the taxonomy given by Bengeleil and Paribakht (2004). The taxonomy is comprehensive and systematic. It can be used as framework for lexical inferencing research and for the in-depth analysis of knowledge sources and clues used by the second language learners in lexical inferencing. 
Table 1. Amended Taxonomy of Knowledge Sources (KSs) Used in Lexical Inferencing

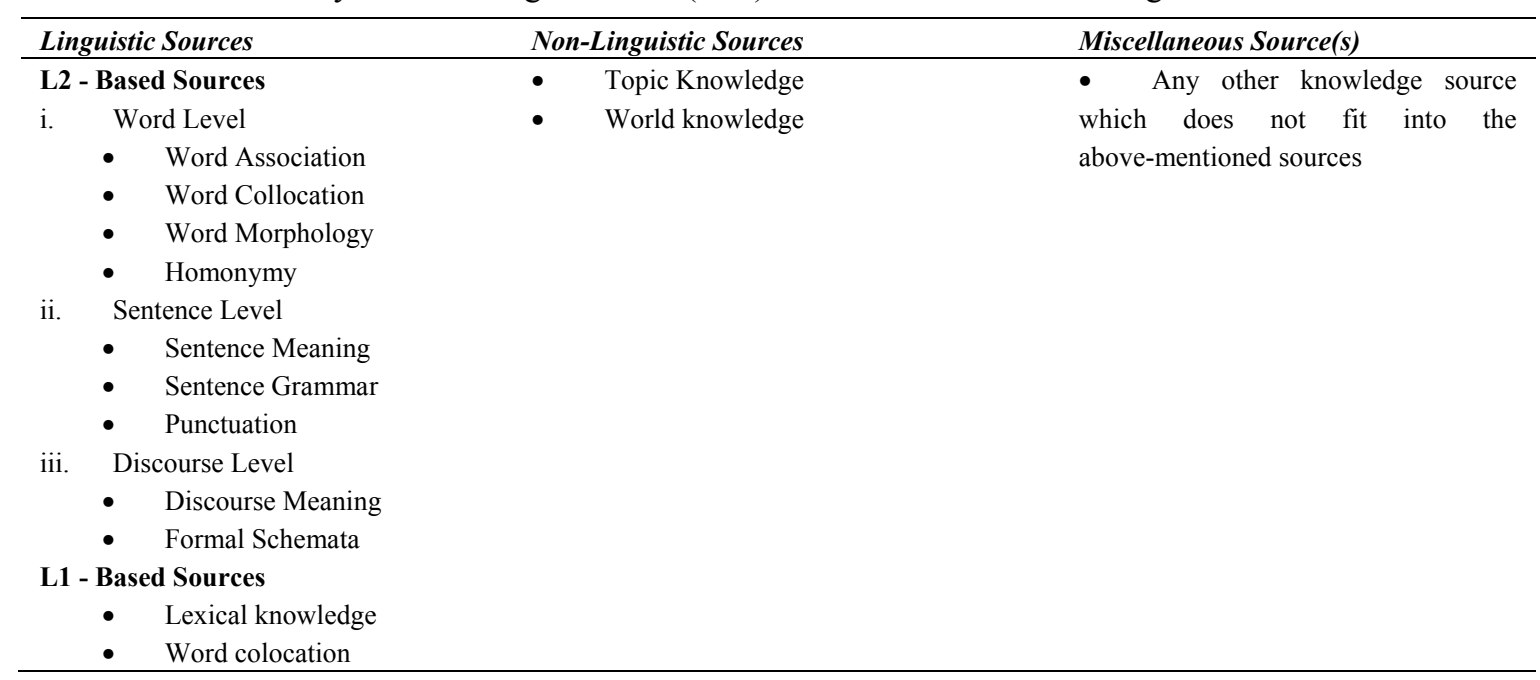

Bengeleil and Paribakht (2004) do not use the words, "cues" or "clues". Instead, they have used knowledge sources (KSs) used in lexical inferencing. In this taxonomy, two major sources are linguistic sources and non-linguistic sources. The linguistic sources are further subcategorized into L2-based sources and L1-based sources. Interalingual sources relate to word level, sentence level and discourse level sources. Interlingual source refers to L1 lexical knowledge and the collocational relationship with the L1 equivalent of the target word. Non-linguistic sources include knowledge of the topic of the text and schemata.

\section{Data Analysis}

\subsection{Qualitative Analysis}

Both groups were told to infer the meanings of 36 unknown words which were written in bold font. Each participant met the researcher individually and attempted to infer the meanings of the unknown words. A coding scheme was developed in order to analyze the verbal protocols of the subjects of the study.

$$
\begin{array}{lll}
\mathbf{P}=\text { Participant } & \mathbf{I}=\text { Instructor } & (\quad)=\text { Guessed Meaning } \\
\ldots=\text { Pause } & \{\quad\}=\text { Use of L1, Urdu here } & \text { Italics }=\text { words taken from the text }
\end{array}
$$

\section{i. Verbal protocols of lower-proficiency group}

\section{Example: 1}

\section{Target Word: Punctuated}

Homonymy

P: Punctuated... Punctured.... Punctured the bad relationship. It

I: What is in your mind?

P: Sir, when bad relation is punctures like tyre...

\{As a result, good relations will come.\}

After uttering the target word, the participant pauses. Then the knowledge source of homonymy is activated. It is the orthographic and sound similarity in the beginning of the target word which leads to another word 'punctured'. In fact, it is the tyre of a vehicle which gets punctured. The participant tries to fit the wrong inference into the context provided in the text. These are the bad relations which get punctured. The participant thinks that the era of the good relations starts. When asked to say more, the participant tries to explain the guess she has made. The syntactic error is made as 'punctures' is uttered instead of punctured. It often happens in the verbal data that grammatical errors are made when speaking abruptly. The participant declares in Urdu that the good relations will come after the bad relations. 
Example: 2

Target Word: Embargo
Sentence Meaning

Word Association

P: Embargo....Moscow may now be willing to lift its embargo on defence supplies to Pakistan... lift its embargo... lift its (restrictions). Defence supplies from Russia... coming to Pakistan... I think the guess is correct.

The target word is uttered and a pause is made by the participant. He reads the complete sentence in which the target word is located. 'Lifting its embargo' leads to the correct inference 'restrictions'. The source of word association also works here. The participant inserts the guessed meaning 'restrictions' in the sentence on the place of the unknown word. Then he makes a pause and again reads the maximum words from the given sentence. These are the defense supplies which were restricted. He is certain of the guess he has made. The neighboring context of the target word has assisted the inferencer to make a successful guess.

Example: 3

Target Word: Embargo

\section{Word Morphology}

Homonymy

Word Collocation

P: Embargo... em is em. Then comes bar... then comes go... bar we know in Urdu.

I: What do you know?

P: It is (burden)... when the burden goes away... No burden to lift.

The participant uses the knowledge source of decomposing the unknown word into parts. The middle part of the targeted word sounds like an Urdu word "bar". When asked to describe her knowledge of a word in Urdu, the participant describes the meaning of the Urdu word "bar". "Bar" in Urdu means "burden". The sound similarity between both the words leads the participant to incorrect guessing. According to her, when burden is removed one finds no burden to lift. It is worth-noticing that the participant has used the word "lift" which occurs as a collocation with "embargo". But all the effort proves unsuccessful as a wrong inference is made.

\section{Example: 4}

Word Morphology

\section{Target Word: Enviable}

P: $\{$ Enviable $\ldots$ in ... viable something which is not viable... What is viable... In viable... No it is not 'in' but 'en', en...viable... nothing is got... a very difficult word to guess.\}

In this verbal data, the participant utters the target word and decomposes it in order to generate its meaning. She mispronounces the unfamiliar word. Without telling the meaning of the word she emphasizes the part 'viable'. She has not made a successful attempt yet. But she notices that she has mispronounced the word. She corrects it, but fails to deduce the meaning of the target word.

\section{ii. Verbal Protocols of Higher-Proficiency Group}

Example: 5

Target Word: Punctuated

P: In this first paragraph, the writer gives the readers the reasons...

I: What do you want to say?

P: Sir, the reasons for unfavourable relations... the word punctuated...Sir, Can we use $\quad$ it as a verb? ... as it is written here. Punctuated has comes from punctuation ... it is stressed ... I mean emphasized here ... I wanna win the game.

\section{Discourse Meaning}

Sentence Grammar 
The participant starts the verbal data from discourse meaning as she mentions the first paragraph. From the beginning the target word is not uttered. On the contrary, the participant focuses the reasons described by the writer. When asked to elaborate more, the participant attends to the reasons which bring about the unfavourable relations between Rusia and Pakistan. After a pause, the participant comes to the target word "punctuated". Over and again, pauses are made by the participant. All this means that the participant is flooded by the thoughts. Respectfully, the participant asks about clarification about the use of the word as verb. The attention is focused on the use of the word as a verb. All of a sudden, the apparent orthographic similarity between "punctuated" and "punctuation" attracts the participant. Then the inferred meanings of the unknown words are described as "stressed" and "emphasized". The successful inferencing is made in the long run.

Example:6

Target Word: Convergent

\section{Homonymy}

Punctuation

\section{Sentence Meaning}

P: $\quad$ Convergent... It is from convert ... I read the sentence. There are two hyphens in the sentence... the part of the sentence where the word comes is after the second hyphen. Hyphens are used to explain the things... the areas Afghanistan, Indo-Pak moralization and counter terrorism... All the countries have the same purposes... They (come to a common point)... It means the (purposes are same)\}.

In the above-mentioned protocol the participant tries to figure out the meaning of the target word with another word 'convert'. Then a pause is made. This knowledge source is rejected as it does not work her. The participant expresses her desire to read the sentence. But she never reads the sentence. The knowledge of punctuation is activated when the participant notices the use of two hyphens there. The function of hyphens is described correctly by the participant. The areas which are similar are read by the participant. The correct inference is arrived at. The combination of three knowledge sources - homonymy, punctuation and sentence meaning - are used one after another until the correct inference is made. The orthographic similarity between 'convergent' and 'convert' is rejected by the participant as it does not work here. Put simply, it does not fit into the context provided in the article.

\section{Example: 7}

\section{Target Word: Traverses}

Sentence Meaning

World Knowledge

\section{P: \{Traverses means (to move or travel in a region).}

I: How do you know that?

P: The instruction... I mean suggestion comes from the writer. Follow it on the map and the road Traverses all the countries in between. What is 'it' in the sentence. It is CPEC.... No... CPEC is for Pakistan and China. As we know ' $\mathrm{C}$ ' is for China, ' $\mathrm{P}$ '. is for Pakistan and ' $\mathrm{E}$ ' is for economic... I have forgotten the last ' $\mathrm{C}$ '. It is for China... no, it is for Corridor (in Urdu we say economic corridor\}. It is OBOR which (moves and travels) all the countries in between.

The inferencer in the beginning of the protocol gives the correct meaning of the difficult word. But she has not mentioned the knowledge source which made her infer successfully. When asked to say something more, she moves to a right direction. The word 'instruction' is replaced by 'suggestion'. The participant not only reads the sentence, but also tries to read the mind of the writer. Then she reads the complete sentence in which the unfamiliar word occurs. Now it is not the difficult word for the participant as she has figured out its meaning in the first shot like an expert batsman. The use of pronoun 'it' attracts the participant. An effort is made to find out as what 'it' refers. The participant thinks that 'CPEC' is mentioned in the sentence. But her world knowledge is activated as she explains the abbreviated word 'CPEC'. Then this inference in comprehension is rejected. The next only option is 'OBOR' which means 'One Belt, One Road' 'CPEC' is meant for China and Pakistan. But 'OBOR' is a larger project than 'CPEC'. 'OBOR' includes many countries. 
Example: 8

Target Word: Gloated

\section{Sentence Meaning}

Discourse Meaning

\section{L1 Word Collocation}

P: $\quad$ It gloated over it as the one great gift... the previous sentences has the offer, not gift... the offer is now gift... What an offer!... In the twinkling of an eye it becomes the gift... yes, ye... It (eyed) over it as the one great gift to Pakistan. I am not sure 'eye' can be used as a verb... if it is an verb... it, is good to use here as 'eyed'... It is more suitable... even more appealing than gloated... The words beginning with ' $\mathrm{g}$ ' are always in the good sense.

I: How can you say so?

P: See 'glitter', 'glamour', 'gleeful'... even 'glimpse'... gloated has the same meaning...Doesn't the same meaning. It is the government of Pakistan which (feasts its eyes) on CPEC greedily, I mean with great interest\}.

The participant reads the complete sentence in which the target word occurs. The word 'gift' in the sentence and the word 'offer' in the previous sentence are noticed. The change of 'offer' into 'gift' is well-observed by the participant. The exclamation of surprise comes in the expression, "What an offer!". The use of idiom "in the twinkling of an eye' is worth-noticing. The inferred meaning 'eyed' is used instead of 'gloated'. She thinks that the use of the verb 'eyed' is more appropriate than 'gloated'. Then the participants enlists connotations of the words beginning with the letter ' $\mathrm{g}$ '. When asked to explain, the participant gives the examples in order to prove her point of view correct. The strategy of giving exemplification works well here. The participant plays the game of inferencing in a skillful manner. The inferred meaning 'feasts its eye..... greedily' is worth-appreciating as it fits into the context provided in the text.

\subsection{Quantitative Analysis}

The quantitative analysis of data was performed in order to answer three research questions of the study. As mentioned earlier, data was collected through introspective method. The participants of the main study were given two column articles which contained 36 unknown words (21 in Pakistan's Moscow Option and 15 in $O B O R$ and $C P E C$ ). They verbalized their thoughts while inferring the meanings of these words. The main objective was to find out the knowledge sources used by them in lexical inferencing task.

Table 2. Proportion of knowledge sources and no knowledge sources by two groups in lexical inferencing

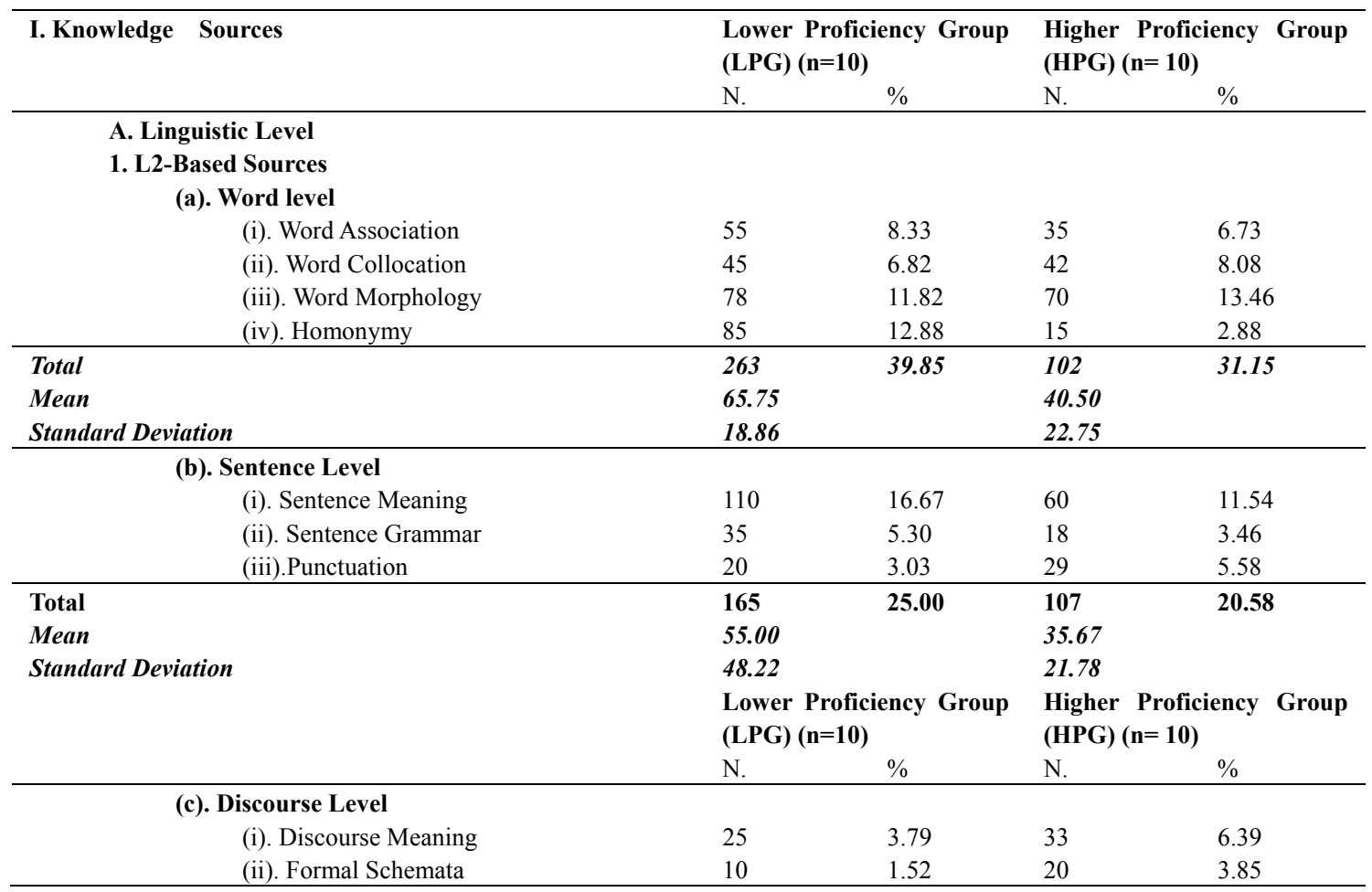




\begin{tabular}{|c|c|c|c|c|}
\hline Total & 35 & 5.30 & 53 & 10.19 \\
\hline Mean & 17.50 & & 26.50 & \\
\hline Standard Deviation & 10.61 & & 9.19 & \\
\hline \multicolumn{5}{|l|}{ 2. L1-Based Sources } \\
\hline (a). Lexical Knowledge & 22 & 3.33 & 28 & 5.39 \\
\hline (b). Word Collocation & 15 & 2.27 & 14 & 2.69 \\
\hline Total & 37 & 5.61 & 42 & 8.08 \\
\hline Mean & 18.50 & & 21.00 & \\
\hline Standard Deviation & 4.95 & & 9.90 & \\
\hline \multicolumn{5}{|l|}{ B. Non-Linguistic Sources } \\
\hline 1. Knowledge of the topic & 62 & 9.39 & 77 & 14.81 \\
\hline 2. World Knowledge & 70 & 10.61 & 67 & 13.27 \\
\hline Total & 132 & 20.00 & 146 & 28.0 \\
\hline Mean & 66.00 & & 72.00 & \\
\hline Standard Deviation & 5.66 & & 7.07 & \\
\hline \multicolumn{5}{|l|}{ II. No Knowledge Sources and Skipping } \\
\hline A. No Knowledge Sources & 8 & 1.21 & 4 & 0.00 \\
\hline B. Skipping & 20 & 3.03 & 6 & 1.92 \\
\hline Total & 28 & 4.24 & 10 & 1.92 \\
\hline Mean & 14.00 & & 5.00 & \\
\hline Standard Deviation & 8.49 & & 1.41 & \\
\hline Grand Total & 660 & 100.00 & 520 & 100.00 \\
\hline
\end{tabular}

As table 2 indicates, lower proficiency group made use of knowledge sources more than higher proficiency group. As noticed in the table, lower proficiency group used 660 knowledge sources while higher proficiency group used 520 knowledge sources in the verbal protocols while using single knowledge sources and combined knowledge sources.

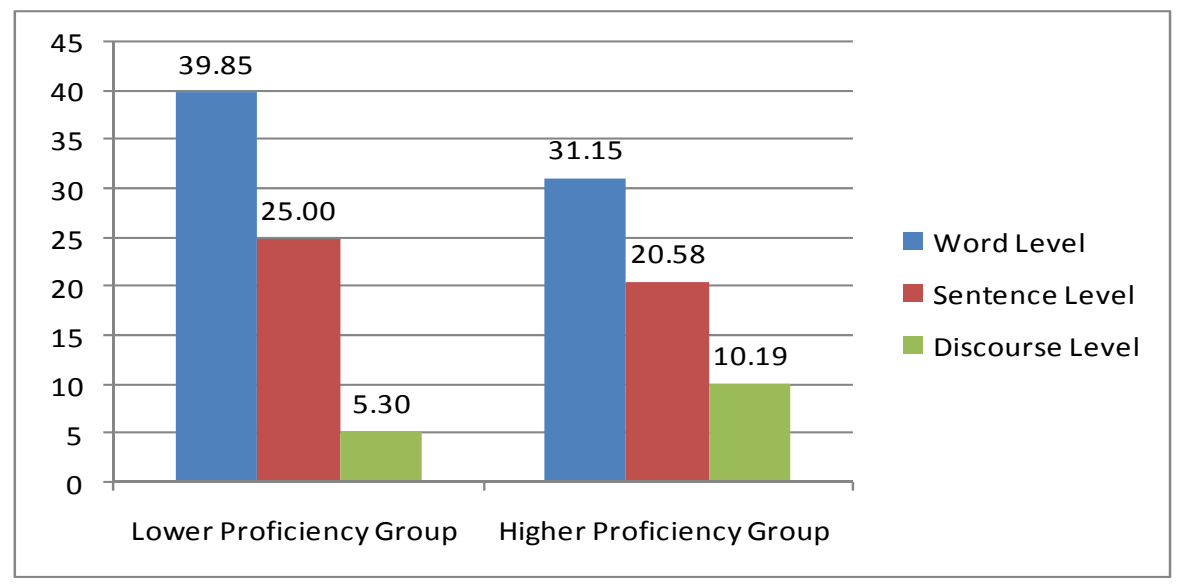

Figure 2. L2 based sources

As figure 2 reveals, the students belonging to lower proficiency group used word level knowledge sources more often than other knowledge sources at this level. They had $39.85 \%$ on word level, $25.00 \%$ on sentence level and $5.30 \%$ on discourse level. Higher proficiency group has $31.15 \%$ on word level, $20.58 \%$ on sentence level and $10.19 \%$ on discourse level. Both groups used more word level knowledge source than sentence level and discourse level knowledge sources. 


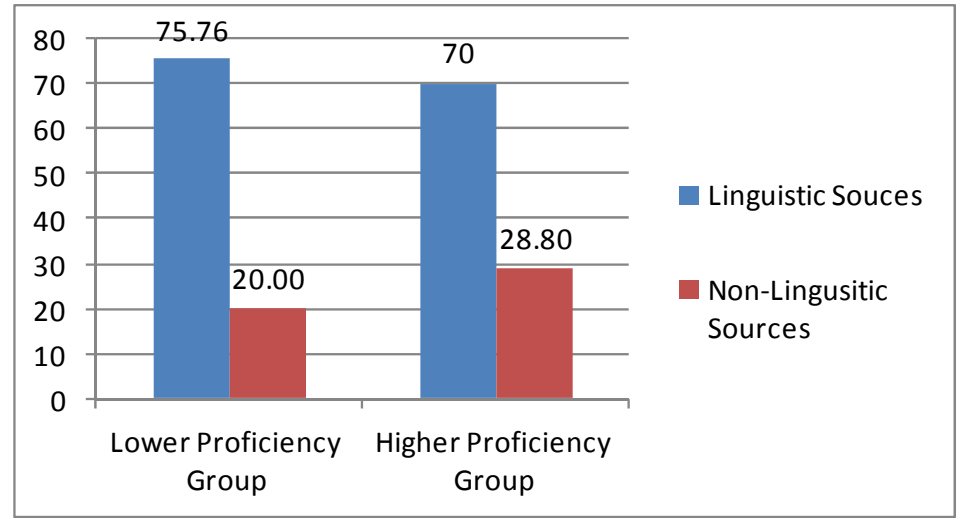

Figure 3. Linguistic sources and non-linguistic sources used by both groups

Linguistic knowledge sources and non-linguistic knowledge sources used by both groups are graphically presented in figure 3. Both groups used linguistic knowledge sources more often than non-linguistic sources. L1 based sources and L2-based sources had $75.76 \%$ for lower proficiency group and non-linguistic sources had $20.00 \%$ for this group. Higher proficiency group had $70.00 \%$ of linguistic sources and $28.8 \%$ of non-linguistic sources.

It is worth-mentioning that the participants of study used single knowledge sources and combined knowledge sources in the task of lexical inferencing assigned to them. The use of the knowledge source of homonymy was higher than that of other sources for lower proficiency group. On the other hand, the use of knowledge of the topics of the newspaper articles was higher than that of other sources for higher proficiency group. Both groups also made use of combined knowledge sources in order to decipher the meanings of the unknown words found in the column articles.

Table 3. Proportion of success and failure in the use of knowledge sources by both groups

\begin{tabular}{|c|c|c|c|c|c|c|c|c|}
\hline \multirow[t]{2}{*}{ I. Knowledge Sources } & \multicolumn{4}{|c|}{ Lower Proficiency Group $(n=10)$} & \multicolumn{4}{|c|}{ Higher Proficiency Group $(n=10)$} \\
\hline & $\underline{\text { Success }}$ & $\underline{\underline{\%}}$ & Failure & $\underline{\%}$ & $\underline{\text { Success }}$ & $\underline{\underline{\%}}$ & Failure & $\underline{\text { \% }}$ \\
\hline \multicolumn{9}{|l|}{ A. Linguistic Level } \\
\hline \multicolumn{9}{|l|}{ 1. L2-Based Sources } \\
\hline \multicolumn{9}{|l|}{ (a) Word level } \\
\hline (i). Word Association & 25 & 3.79 & 30 & 4.55 & 29 & 5.58 & 6 & 1.15 \\
\hline (ii). Word Collocation & 14 & 2.12 & 31 & 4.70 & 35 & 6.73 & 7 & 1.35 \\
\hline (iii). Word Morphology & 28 & 4.24 & 50 & 7.58 & 52 & 10.0 & 18 & 3.46 \\
\hline (iv) Homonymy & 7 & 1.06 & 78 & 11.82 & 4 & 0.77 & 11 & 2.12 \\
\hline Total & 74 & 11.21 & 189 & 28.64 & 120 & 23.08 & 42 & 8.08 \\
\hline Mean & 18.50 & & 47.25 & & 30.00 & & 10.50 & \\
\hline Standard Deviation & 9.75 & & 22.47 & & 19.88 & & 5.45 & \\
\hline \multicolumn{9}{|l|}{ (b). Sentence Level } \\
\hline (i). Sentence Meaning & 40 & 6.06 & 70 & 10.61 & 48 & 9.23 & 12 & 2.31 \\
\hline (ii). Sentence Grammar & 20 & 3.03 & 15 & 2.27 & 15 & 2.88 & 3 & 0.58 \\
\hline (iii). Punctuation & 12 & 1.82 & 8 & 1.21 & 9 & 1.73 & 20 & 3.85 \\
\hline Total & 72 & 10.91 & 93 & 14.09 & 72 & 13.85 & 35 & 6.73 \\
\hline Mean & 24.00 & & 31.00 & & 24.00 & & 11.67 & \\
\hline Standard Deviation & 14.42 & & 33.96 & & 21.00 & & 8.50 & \\
\hline \multicolumn{9}{|l|}{ (c). Discourse Level } \\
\hline (i) Discourse Meaning & 9 & 1.36 & 16 & 2.42 & 27 & 5.19 & 6 & 1.15 \\
\hline (ii). Formal Schemata & 6 & 0.91 & 4 & 0.61 & 6 & 1.15 & 14 & 2.69 \\
\hline Total & 15 & 2.27 & 20 & 3.03 & 33 & 6.35 & 20 & 3.85 \\
\hline Mean & 7.50 & & 10.00 & & 16.5 & & 10.00 & \\
\hline Standard Deviation & 2.12 & & 8.49 & & 14.85 & & 5.66 & \\
\hline \multicolumn{9}{|l|}{ 2. L1-Based Sources } \\
\hline (a) Lexical Knowledge & 12 & 1.82 & 10 & 1.52 & 21 & 4.04 & 7 & 1.35 \\
\hline (b).Word Collocation & 9 & 1.36 & 6 & 0.91 & 11 & 2.12 & 3 & 0.58 \\
\hline Total & 21 & 3.18 & 16 & 2.42 & 32 & 6.15 & 10 & 1.92 \\
\hline Mean & 10.50 & & 8.00 & & 16.00 & & 5.00 & \\
\hline Standard Deviation & 2.12 & & 2.83 & & 7.07 & & 2.83 & \\
\hline
\end{tabular}




\begin{tabular}{|c|c|c|c|c|c|c|c|c|}
\hline \multicolumn{9}{|l|}{ B. Non-Linguistic Sources } \\
\hline 1. Knowledge of the topic & 44 & 6.67 & 18 & 2.73 & 69 & 13.27 & 8 & 1.54 \\
\hline 2. World Knowledge & 50 & 7.58 & 20 & 3.03 & 46 & 8.85 & 23 & 4.42 \\
\hline Total & 94 & 14.24 & 38 & 5.76 & 115 & 22.12 & 31 & 5.96 \\
\hline Mean & 47.00 & & 19.00 & & 57.5 & & 15.5 & \\
\hline Standard Deviation & 4.24 & & 1.41 & & 16.26 & & 10.61 & \\
\hline \multicolumn{9}{|l|}{ II. No Knowledge Sources and Skipping } \\
\hline A. No Knowledge Sources & 6 & 0.91 & 2 & 0.30 & 3 & 0.58 & 1 & 0.19 \\
\hline B. Skipping & 0 & 0 & 20 & 3.03 & 0 & 0 & 6 & 1.15 \\
\hline Total & 6 & 0.91 & 22 & 3.33 & 3 & 58.0 & 7 & 1.35 \\
\hline Mean & 3.00 & & 11.00 & & 1.50 & & 3.50 & \\
\hline Standard Deviation & 4.24 & & 12.73 & & 2.12 & & 3.54 & \\
\hline Grand Total & 282 & 42.73 & 378 & 57.27 & 375 & 72.12 & 145 & 27.88 \\
\hline
\end{tabular}

As mentioned earlier, both lower proficiency group and higher proficiency group used single knowledge sources as well as combined knowledge sources for guessing the meanings of the unknown words. Lower proficiency group used knowledge sources and no knowledge sources for 660 times. Whereas higher proficiency group used knowledge sources and no knowledge sources for 520 times. It means higher proficiency group used less knowledge sources than those of the lower proficiency group.

Table 4. Proportion of success and failure in Pakistan's Moscow Optionand OBOR and CPEC

\begin{tabular}{|c|c|c|c|c|c|c|c|c|}
\hline \multirow{4}{*}{ 1. Lower Proficiency Group } & \multicolumn{4}{|c|}{ Pakistan's Moscow Option } & \multicolumn{4}{|c|}{ OBOR and CPEC } \\
\hline & \multicolumn{2}{|c|}{ Success } & \multicolumn{2}{|c|}{ Failure } & \multicolumn{2}{|c|}{ Success } & \multicolumn{2}{|c|}{ Failure } \\
\hline & $\underline{\mathbf{N}}$ & $\%$ & $\underline{\mathbf{N}}$ & $\%$ & $\underline{\mathbf{N}}$ & $\%$ & $\underline{\mathbf{N}}$ & $\%$ \\
\hline & 84 & $40 \%$ & 126 & $60 \%$ & 68 & $45.33 \%$ & 82 & 54.67 \\
\hline \multirow[t]{2}{*}{ 2. Higher Proficiency Group } & $\underline{\mathbf{N}}$ & $\%$ & $\underline{\mathbf{N}}$ & $\%$ & $\underline{\mathbf{N}}$ & $\%$ & $\underline{\mathbf{N}}$ & $\%$ \\
\hline & 135 & $64.29 \%$ & 75 & $35.71 \%$ & 110 & $73.33 \%$ & 40 & $26.67 \%$ \\
\hline
\end{tabular}

As indicated in table 4, both lower proficiency group and higher proficiency group were more successful in OBOR and CPEC article than Pakistan's Moscow Option. As mentioned before, Pakistan's Moscow Option article was more lengthy than OBOR and CPEC article. The percentage of success (40\% in Pakistan's Moscow option for lower proficiency group was less than that of OBOR and CPEC article (45.33\%). Higher proficiency group was made also more successful attempts (73.33\%) in OBOR and CPEC than those (64.29\%) of Pakistan's Moscow Option. The results of the quantitative analysis of success and failure of both groups in the articles reveal that text length has significant effect in the task of lexical inferencing.

Table 5 Proportion of success and failure in verbs, nouns and adjectives

\begin{tabular}{|c|c|c|c|c|c|c|c|c|}
\hline \multirow[b]{3}{*}{ 1. Verbs } & \multirow{2}{*}{\multicolumn{2}{|c|}{$\begin{array}{l}\text { Lower Proficiency Group } \\
(\mathrm{N}=10) \\
\text { Success }\end{array}$}} & & & \multirow{2}{*}{\multicolumn{2}{|c|}{$\begin{array}{l}\text { Higher Proficiency Group } \\
(\mathrm{N}=10) \\
\text { Success }\end{array}$}} & \multirow{2}{*}{\multicolumn{2}{|c|}{ Failure }} \\
\hline & & & \multicolumn{2}{|c|}{ Failure } & & & & \\
\hline & $\underline{\mathrm{N}}$ & $\%$ & $\underline{N}$ & $\%$ & $\underline{N}$ & $\%$ & $\underline{\mathrm{N}}$ & $\%$ \\
\hline & 85 & $53.13 \%$ & 75 & $46.87 \%$ & 112 & $70.00 \%$ & 48 & $30.00 \%$ \\
\hline \multirow[t]{2}{*}{ 2. Nouns } & $\underline{\mathrm{N}}$ & $\%$ & $\underline{\mathrm{N}}$ & $\%$ & $\underline{\mathrm{N}}$ & $\%$ & $\underline{\mathrm{N}}$ & $\%$ \\
\hline & 55 & $42.31 \%$ & 75 & $57.69 \%$ & 80 & $61.54 \%$ & 50 & $38.46 \%$ \\
\hline \multirow[t]{2}{*}{ 3. Adjectives } & $\underline{N}$ & $\%$ & $\underline{N}$ & $\%$ & $\underline{N}$ & $\%$ & $\underline{\mathrm{N}}$ & $\%$ \\
\hline & 22 & $31.43 \%$ & 48 & $68.57 \%$ & 38 & $54.29 \%$ & 32 & $55.71 \%$ \\
\hline
\end{tabular}

There were 16 verbs, 13 nouns and 7 adjectives in the texts of main study. No adverb was found difficult in the texts of the main study. There were 36 target words. In the main study there were 720 verbal protocols in all. 
As table 5 reveals the target words used as verbs in Pakistan Moscow Option and OBOR and CPEC gave more successful inferences than those of nouns and adjectives. Lower proficiency group had $53.13 \%$ success whereas higher proficiency group had $70.00 \%$ success in inferring the meanings of target words which were verbs. Nouns ranked second as lower proficiency group had 42.31 percentage of success and higher proficiency group had 61.54 percentage of success. The participants of study were not comfortable in dealing with adjectives as their percentage of failure reveals. Lower proficiency group had 68.56 percentage of failure in guessing the meanings of adjectives while higher proficiency group had 45.71 percentage of failure in deciphering the meanings of the targeted adjectives.

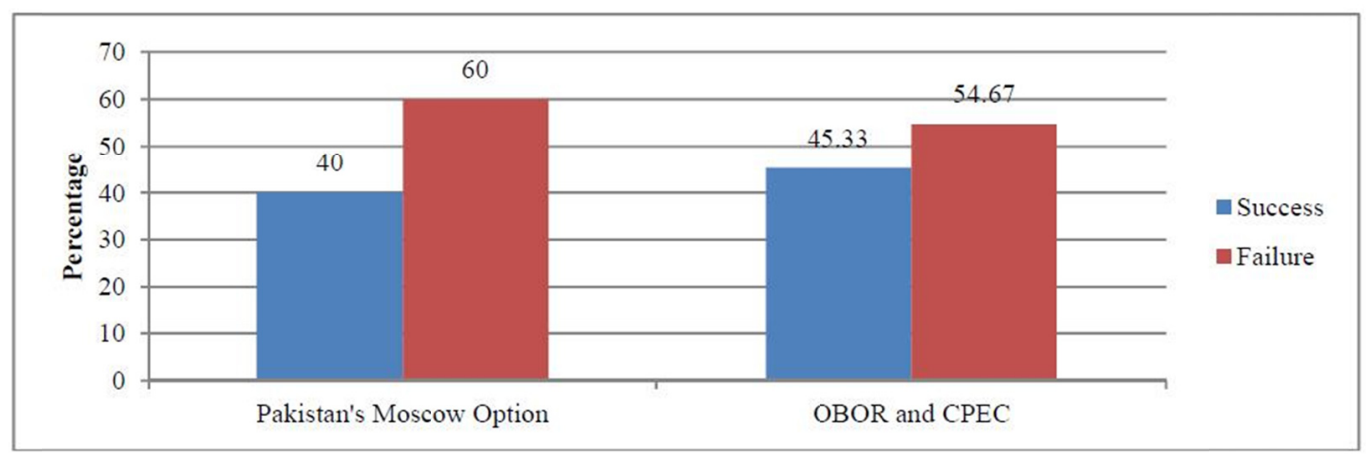

Figure 4. Proportion of success and failure of lower proficiency group

The figure 4 reveals that students of lower groups were more successful in their attempts to infer the meanings of the unknown words in OBOR and CPEC than those of Pakistan's Moscow Option.

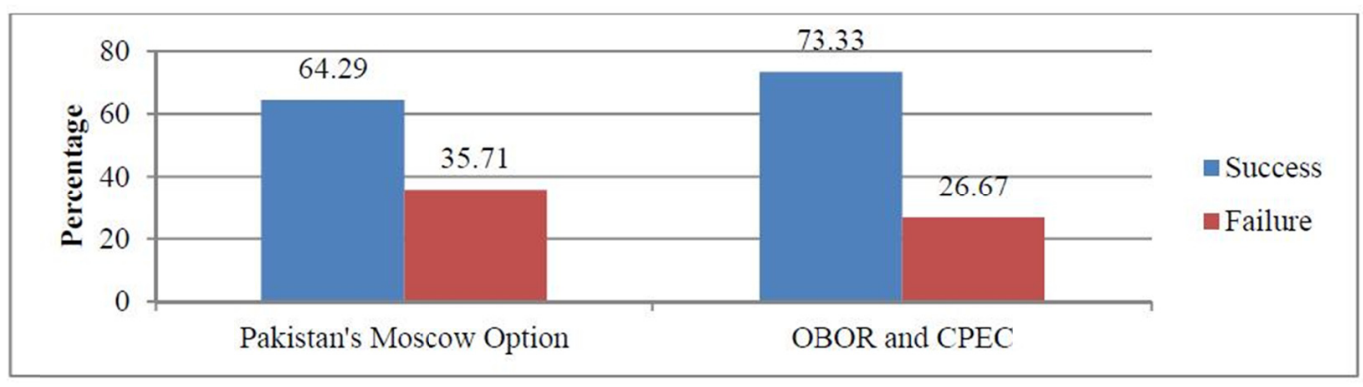

Figure 5. Proportion of success and failure of higher proficiency group

Figure 5 shows that higher proficiency group made more successful attempts in $O B O R$ and $C P E C$ than those of Pakistan's Moscow Option as the difference in the percentage of success 64\% in Pakistan's Moscow Option and $73.33 \%$ in $O B O R$ and $C E P C$ has revealed.

\section{Findings}

The higher proficient group relied more on non-linguistic sources than lower proficient group. The lower level students were more entrapped by homonymy than their seniors. Most of the senior students were aware of the fact that difference in spellings meant difference in meaning.

As far as the rate of success in lexical inferencing is concerned, higher proficient group was more successful than lower-proficient group. Most of the senior students were flexible in the use of knowledge sources. Both the groups used single knowledge source and combined knowledge sources. It was observed that successful inferencers from both groups generated hypotheses for the target words, used contextual clues (both intra- word and inter-word) and evaluated their guesses while putting them in the context provided in the texts. Strategic inferencers even felt pleasure in finding out the meanings of the target words assigned to them.

The participants of the study were more successful in $O B O R$ and $C P E C$. This article was less lengthy than 
Pakistan's Moscow Option. All the unknown words were present on only one page. The participants of the study were comfortable in finding out the discourse meaning when the other knowledge sources failed to give contextual clues to the target word. Resultantly, the length of text has impact on the process of lexical inferencing.

Findings of the study revealed that word factor has effect on the process of lexical inferencing. Verbs were found to be the easiest to guess. Nouns ranked second. Adjectives were found difficult as far as guessing is concerned. The results of study are different from Lennon's study (1996). The present study has revealed that the participants of the study were comfortable in guessing the meanings of the target words which were verbs. They were more successful in deciphering the meanings of the verbs than nouns and adjective. Nouns were also found to be more successful in guessing than adjectives. The results of the present study are in consistent with Schmitt's study (1998). He has pointed out that learners are more likely to know nouns and verbs than adjectives or adverbs. The studies of Lennon and Schmitt were basically concerned with the learning of the parts of speech rather than guessing words in an L2 context. Nation (1990) has suggested that the nouns and verbs are easier to guess than adjectives and adverbs. Another plausible reason of success in verbs is that the whole sentence depends on verb while offering various clues to it. It was remarked by one of the participants in the study that "verbs is the soul of a sentence."

\section{Recommendations}

- In ESL classrooms more attention should be given to lexical inferencing due to its significance in reading comprehension. Furthermore, it should be incorporated in reading classes. It will facilitate reading comprehension and enhance vocabulary knowledge of learners.

- When learners generate a hypothesis deducing the meaning of a new word, they should activate other knowledge sources in order to check and double-check the hypothesis they have made. Such critical outlook will improve their lexical behaviour.

- Learners should find out the connection between contextual information and the unknown word. Unsuccessful inferencers do the opposite as they use the unfamiliar word to infuse meaning into the larger stretch of language in which it is embedded (Wolter, 2009, p.129).

- A well-planned strategic ability in lexical inferencing results in effective and beneficial inferencing. As Koda (2004, p.68) has suggested that learners should "first formulate sentence-level understanding from linguistic cues, and then coalesce information with their prior knowledge to deduce the semantic gap created by the unknown word."

- When learners are motivated, they engage in the process of learning for its own sake (Wade et al., 1999). Teachers should try to stimulate interest in learners. They should inform learners that lexical inferencing is like an attempt to find out a thing that is lost. While using various clues, learners are able to find the lost thing.

- Mental lexicon is regarded as a dense network of connections among words (Meara, 2009). Teachers should elicit the judgments of learners about associative links between words. Koda (2004, p. 68) has suggested that "the stronger the connections, the more rapidly and accurately lexical information is accessed and retrieved".

\section{Conclusion}

Vocabulary knowledge should be regarded as a continuum between ability to make sense of a word and ability to activate the word automatically to productive purposes (Farech et al. 1984, p. 100). Lexical inferencing is a significant factor in facilating the process of lexical knowledge of the target language. It will be better if teacher avoids providing meaning for every unknown word the learners encounter during reading in L2 texts. Even the strategies learnt in the classroom can be applied in real-life situations outside the classroom. What is needed is motivation in learning the target language. In this regard Chamot et al. (1996, p. 178) have pointed out that "highly motivated students work hard, preserve in the face of difficulties and find satisfaction in the accomplishment of a learning task." A strategic inferencer activates his/her schemata and explicit and implicit text information in order to deal with new lexical items. Resultantly, readers' comprehension of textual information is enhanced. The strategic readers construct meaning from the textual information provided to them. Meek (1988, p. 37) has remarked that "what is happening to the reader is as important as the text itself." The selection of appropriate and authentic texts should be based on an understanding of the needs of learners. Their needs can be best understood when teachers keep in mind the level of engagement a text produces.

The guessed meanings should be checked against the context (Schouten-van Parrern, 1992). Both top-down 
processing and bottom-up processing are important factors in comprehending texts. Once the morphological analysis of a target word is made, it should be supported with the context provided in a text. If not, other knowledge sources should be used in order to compensate for the lexical deficiencies learners have. As lexical inferencing is a complex cognitive task (Wesche \& Paribakht, 2009), learners should be advised to make careful use of knowledge sources in lexical inferinceing task. The sane repertoire of knowledge sources in deciphering the meanings of the unknown words can augment lexical development. Learners' lexical inference ability and knowledge source interact with their proficiency in L2 reading. The lexical network is built on similarities and differences found in L1 vocabulary and L2 vocabulary. The network develops with the passage of time. Words used in multiple contexts enhance the semantic richness as each new episode helps learners develop lexical entries for words as far as form, meaning and use are concerned (Craik, 2007). The deeper the processing of lexical items, the better the lexical competence of learners will be. Such processing contributes to the development of richer lexical representations in the mental lexicon of learners.

\section{References}

Bailystock, E., \& Kellerman, E. (1987). Language strategies in the classroom. In B. K. Das (Ed.), Communication and learning in the classroom community (pp. 160-175). Singapore: SEAMEO Regional Language Centre.

Bengeleil, N. F., \& Paribakht, T. S. (2004). L2 reading proficiency by university EFL learners. The Canadian Modern Language Review, 61, 225-249. https://doi.org/10.3128/Cmlr.61.2.225

Bensoussan, M., \& Laufer, B. (1984). Lexical guessing in context in EFL reading comprehension. Journal of Research in Reading, 7, 15-32. https://doi.org/10.1111/j.1467-9817.1984.tb00252.x

Carton, A. (1971). Inferencing: A process in using and learning language. In P. Pilmsleur \& T. Quinn (Eds.), The psychology of second language learning (pp. 45-48). Cambridge: Cambridge University Press.

Chamot, A. V., Barhardt, S., El-Dinary, P., \& Robbins, J. (1996). Methods for teaching learning strategies in the foreign classroom. In R. Oxford (Ed.), Language learning strategies around the world: Cross-cultural prospective (pp. 175-188). Huwai: Second Language Teaching \& Curriculum Centre.

Craik, F. I. M. (2007). Encoding: A Cognitive Perspective. In H. L. Roedigar, Y. Dudai, \& S. M. Fitzpatrik (Eds.), Science of memory: Concepts (pp. 129-135). Oxford: Oxford University Press.

Deschambault, R. (2012). Thinking-aloud as talking-in-interaction: Reinterpreting how L2 lexical inferencing gets done. Language Learning, 62(1), 266-301. https://doi.org/10.1111/j.1467-9922.2011.00653.x

Elgort, I. (2017). Incorrect inferences and contextual word learning in English as a second language. Journal of the European Second language Acquisition, 1(1), 1-11. https://doi.org/10.22599/jesla.3

Ericson, A. K., \& Simon, H. A. (1993). Protocol analysis: Verbal reports as data. London: MTI Press.

Farech, K., Haastrup, K., \& Phillipson, R. (1984). Learner language and language learning. Cevedon, England: Multilingual Matters.

Haastrup K. (1991). Lexical inferencing procedures or talking about words: Receptive procedures in foreign language learning with special reference to English. Tubingen, Germany: Gunter Narr.

Haastrup, K. (1989). The learner as a word processor. AILA Review, 6, 34-46.

$\mathrm{Hu}$, M., \& Nassaji, H. (2012). Ease of inferencing: Learner inferential strategies and their relationship with the retention of word meanings inferred from context. The Canadian Modern Language Review, 68(1), 54-77. https://doi.org/10.3138/cmlr.68.1.054

Hu, M., \& Nassaji, H. (2014). Lexical inferencing strategies: The ease of successful versus less successful inferencers. System, 45, 27-38. https://doi.org/10.1016/j.system.2014.04.004

Huckin, T., \& Bloch, J. (1993). Strategies for inferring word meaning from context: A cognitive model. In T. Huckin, M. Haynes, \& J. Coady (Eds.), Second language reading and vocabulary learning (pp. 153-178). Noorwood, NJ: Ablex.

Jelic, A-B. (2007). Lexical inferencing strategy use by Croatian foreign language learners. In J. Horvath \& M. Nikolov (Eds.), UPRT 2007: Empirical studies in English applied linguistics (pp. 245-254). Pecs: Lingua Frenca Csoport.

Koda, K. (2004). Insights into second language reading: A cross-linguistic approach. Cambridge: Cambridge University Press. 
Lennon, P. (1996). Getting 'easy' verbs wrong at the advanced level. IRAL, 34, 23-36. https://doi.org/10.1515/iral.1996.31.1.23.

Meara, P. (2009). Connected words: Word associations and second language vocabulary acquisition. Amsterdam: Benjamins. https://doi.org/10.1075/11lt.24

Meek, M. (1988). How texts teach what readers learn. Stroud: Tumble Press.

Nassaji, H. (2003). L2 vocabulary learning from context: Strategies, knowledge sources, and their relationship with success in L2 lexical inferencing. TESOL Quarterly, 37, 645-670. https://doi.org/10.2307/3588216

Nassaji, H. (2004). The relationship between depth of vocabulary knowledge and L2 learners' lexical inferencing strategy use and success. Canadian Modern Language Review, 61(1), 107-134. https://doi.org/10.3138/cmlr.61.1.107

Nation, I. S. P. (1990). Teaching and learning Vocabulary. New York: Newbury House.

Payan, A. K. (1994). Thinking aloud: Insights into information processing. Psychological studies, 5, 241-244. https://doi.org/10.1111/j.1467-9280.1994.tb00620.x

Qian, D. D. (2005). Demystifying lexical inferencing: The role of aspects of vocabulary knowledge. TESL Canada Journal, 22(2), 34-54. https://doi.org/10.18806/tesl.v22i2.86

Schmitt, N. (1998). Tracking the incremental acquisition of second language vocabulary: A longitudinal study. Language Learning, 8(2), 281-317. https://doi.org/10.1111/1467-9922.00042

Schouten-van Parrern, C. (1992). Individual differences in vocabulary acquisition: A qualitative experiment in the first phase of secondary education. In P. Arnand \& H. Bejoint (Eds.), Vocabulary and Applied linguistics (pp. 94-101). Basingstoke: Macmillan. https://doi.org/10.1007/978-1-349-12396-4_9

Wade, S. E., Buxton, W. M., \& Kelly, M. (1999). Using think-aloud to examine reader-text interest. Reading Research Quarterly, 34(2), 194-216. https://doi.org/10.1598/RRQ.34.2.4

Wesche, M., \& Paribakht, T. S. (2010). Lexical inferencing in a first and second language: Cross-linguistic dimensions. Bristol, UK: Multingual Matters.

Wolter, B. (2009). Meaning-last vocabulary acquisition and collocation productivity. In T. Fitzpartick \& A. Barfield (Eds.), Lexical processing in second language learners: Papers and perspectives in honour of Paul Meara (pp. 128-140). Bristol: Multilingual Matters. https://doi.org/10.21832/9781847691538-012

\section{Appendix A}

\section{Pakistan's Moscow Option}

SINCE independence, Pakistan's relations with Moscow have been mostly unfavourable. Pakistan was America's "most allied ally". India aligned with the Soviet Union during the Cold War. Moscow's veto in the UN Security Council to block Kashmiri self-determination, the U2 flight from Peshawar, Soviet support in 1971 for India's war to dismember Pakistan and Islamabad's cooperation with the US in the anti-Soviet war in Afghanistan punctuated the unfavourable relationship.

Although the hostility slowly dissipated after the fall of the Soviet Union, friendship eluded Moscow and Islamabad, for different reasons: Russia's continuing defence relationship with India, Pakistan's support for the Afghan Taliban - and by extension their Chechen and Uzbek frinds-Moscow's alignment with the Northern Alliance and Pakistan's post 9/11 alliance with the US.

However, the new 'Cold War' in Europe, ignited by the Ukraine crisis, has profound strategic implications not only for Europe but also for other 'theatres' where Russia's interests and objectives intersect with those of the US and Europe. Sino-Russian relations have become surprisingly closer. Moscow is maintaining its role in the Middle East. It is also likely to do so in East and South Asia. Pakistan-Russia relations have been moving in positive directions during recent months. Pakistan is acting against Central Asian terrorists. As India has moved closer to the US, Russia has come closure to Pakistan. The closer Sino-Russian relationship has reinforced this trend. There are clear signs that Moscow is now open to substantive security cooperation with Pakistan. Russia's aims are: to secure Pakistan's cooperation to stabilise Afghanistan, fight against Chechen and Central Asian terrorist groups present in the region, compensate for India's tilt towards America and thereby have leverage in New Delhi.

There are a number of areas where useful cooperation can be promoted between Islamabad and Moscow. 
Afghanistan: Over the past year, secret talks between Pakistan, China and Russia have been under way to stabilise Afghanistan. Russia's old relationship with the Northern Alliance and influence with Iran; Pakistan's influence with the Pakhtuns and the Afghan Taliban; and China's financial and economic capacity can be a powerful combination to promote peace in Afghanistan as the US leaves of Afghanistan.

Indo-Pakistan: As India's major defence partner and a member of BRICS, Moscow continues to enjoy much, influence in India inspite of New Delhi's tilt towards the US. Russia desires Indo-Pakistan normalisation to prevent a dangerous conflict, limit American influence and develop new ways for energy, trade and industrial cooperation with the South Asian region. Given the new global political relationship, Moscow's mediation between India and Pakistan could be more equally treated and effective than the skewed policies made by Washington.

Defence: Russia's defence industry is still among the best in the world. Moscow may now be willing to lift its embargo on defence supplies to Pakistan. The directions of such cooperation will depend mainly on Pakistan's ability to pay for defence equipment and, on the strength of New Delhi's anticipated objections.

Oil and gas: Russia is the world's largest producer of oil and gas. The expertness of Russia's Rosneft and Gazprom can contribute importantly to developing Pakistan's oil and gas potential, onshore and offshore. Western approval has made these big Russian companies find new ways of cooperation.

Gas supplies: After the Western embargoes, Russia is looking for other markets for its excessive gas production. Its $\$ 400$ billion gas deal with China has been the most main response. Moscow is also interested in building gas supply routes to India and Pakistan. Russian gas could be added to supplies from the proposed TAPI pipeline. New pipelines can be built to Pakistan and India through China. Russia's Gazprom could also help in completing the projected Iranian gas pipeline to Pakistan (and India).

Nuclear reactors: So far, Russia has refused to supply nuclear power reactors to Pakistan due to the restrictions of the Nuclear Suppliers' Group on non-members of the NPT-with the major exception of India. It is possible that in the new strategic circumstances, and in exchange for suitable safeguards, Russia, like China, may consider the sale of nuclear power plants to Pakistan, especially if India gets its new plants from the US.

Trade: If Afghanistan can be stabilised, it would open the way for expanded trade between Pakistan, Central Asia and Russia. While Pakistan needs Russian oil, gas and industrial products, Pakistan send agricultural and textile goods to Russia. Pakistan could also offer Russia trade access to India in exchange for its help in improving Pakistan-India relationship. Industrialisation: Russia has some of the industrial prowess of the Soviet Union. It can modernise the Soviet-supplied Pakistan Steel Mills. Similar cooperation can be made in a number of 'high-tech' sectors, such as biotechnology, aircraft and space, where Russia has competitive skills.

In some areas - such as Afghanistan, Indo-Pakistan normalisation and counterterrorism - the purposes of the US and its allies are convergent with Russia's. In other areas — energy, defence, nuclear generation—opposition can be expected from the West to Pakistan-Russian cooperation. India may also object, although its opposition may not be effective.

While Pakistan no longer requires, nor is likely to receive, US arms supplies or nuclear power plants, its ability to stop Western objections to cooperation with Moscow could be restricted by its financial and trade dependence on the West. Pakistan's financial stress may also limit its ability to pay for Russian supplies of defence and other equipment.

Pakistan needs to identify realistic aims for its new relationship with Russia, have sustainable ways to minimise its financial vulnerability (including greater financial cooperation with China) and use adroit diplomacy to capitalise on the global and regional strategic realities. Of course, while its politicians squabble on the streets, adding to the country's turbulence, it is difficult for Pakistan to make good policies to use the Moscow option or other strategic benefits.

\section{Appendix B}

\section{OBOR and CPEC}

ANALYSING everything in its correct perspective is a great gift; the loss of perspective is akin to losing one's way in a forest. Keeping perspective helps one walk on the straight and narrow path. Ordinary citizens normally give value to their governments for their actions and decisions, supposing that they are the results of careful thoughts.

The word 'minister' (or wazir) raises up the image of famed wazir, in the courts of kings; the great wisdom of their advice supporting their leaders. So what the huddle of wazirs, also known as the cabinet, decides is beyond 
any criticism. Governments sometimes have perspective and sometimes do not. But they have the enviable choice of presenting their case to their component with or without perspective. The toiling people do not have the time to investigate further. Those with lives of ease do not care beyond satisfying their own interests. The educated persons react depending on which side of the powers-that-be they are responding to.

China, no doubt, has remained a friend to Pakistan. It is their geopolitical need as well as ours - there is no more to it. Countries' relations are subject to change depending on the state of international affairs. During state visits, leaders describe their mutual relations in exaggeration but this is just to sound warm and sweet. The China-Pakistan Economic Corridor (CPEC) is one such example of a story told to the people without any perspective.

Putting it into perspective, CPEC is part of China's grand vision, known as the One Belt, One Road (OBOR) initiative. This vision extends from the Baltics in Europe to Southeast Asia and from China to Africa. Follow it on the map and the road traverses all the countries in between. It is not a physical road like the Silk Road, that historic trade route from China to Europe. That old Silk Road was not like Sher Shah Suri's road from Peshawar to Kolkata, but caravans meandering on different routes from one inn to another, carrying both goods and ideas. China has accumulated $\$ 3.2$ trillion in foreign exchange. It can be used both for investment and to buy influence around the world.

This is what OBOR is about. As an official policy, OBOR is supervised by China's powerful National Development and Reform Commission and the ministries of foreign affairs and commerce, as approved by the State Council, the nation's chief administrative body. OBOR has become the 'in' thing to be linked with in China's world economic strategy. As the word 'road' itself suggests, projects (especially those having construction of physical infrastructure) that improve commerce between China and the wider world community reflect the basic spirit of OBOR. The major difference is that China's belt-road is not based on aid or even FDI, but on loan financing. This underscores the importance, for investors and debtors alike, to carefully factor in danger with OBOR projects.

The recipients of OBOR plans in Africa are Kenya, Tanzania and Zimbabwe. Eastern Europe presents the farthest geographic expansion of OBOR, and of China's reach in historically more advanced capitalist economies. In Poland, a railway project was started in 2013. Hungary has become the first EU member-state to start a Chinese high-speed rail project under OBOR. Russia and China are cooperating on the huge Power of Siberia gas pipeline project. In Southeast Asia, one of the most recent OBOR rail projects to be started is the high-speed railroad (costing $\$ 6$ billion) connecting the Laotian capital of Vientiane to China. A rail project has also been completed in Indonesia. Without surprise, China has won the practicability of two other railway projects-Mumbai to New Delhi and New Delhi to Chennai.

Pakistan's resource-hungry government ogled at the offer of CPEC. It gloated over it as the one great gift to Pakistan. Politics always overrule economics. The ruling party was, therefore, in a great hurry to talk on these projects under secrecy, much to the chagrin of KP and Balochistan, as spending will now affect results in the 2018 national elections. In spite of the mad hurry for the start and completion of the project, it is openly understood that economic analyses for different projects have yet to be made. Lending under CPEC is short-term - it will have serious results for the current account when it is time to repay them in the not-too-far future.

CPEC, a part of OBOR, offers great strategic advantage to China as it gets physical access to the Indian Ocean and closer proximity to Middle Eastern oil resources. Other OBOR projects around the world do not offer such advantages to China. This is a clever global strategic move. China's global enemies will, of course, factor this in their reactions.

\section{Copyrights}

Copyright for this article is retained by the author, with first publication rights granted to the journal.

This is an open-access article distributed under the terms and conditions of the Creative Commons Attribution license (http://creativecommons.org/licenses/by/4.0/). 